\title{
The Proteasome-Associated Deubiquitinating Enzyme Usp14 Is Essential for the Maintenance of Synaptic Ubiquitin Levels and the Development of Neuromuscular Junctions
}

\author{
Ping-Chung Chen, ${ }^{1}$ Lu-Ning Qin, ${ }^{2}$ Xiao-Ming Li, ${ }^{2}$ Brandon J. Walters, ${ }^{1}$ Julie A. Wilson, ${ }^{1}$ Lin Mei, ${ }^{2}$ and Scott M. Wilson ${ }^{1}$ \\ ${ }^{1}$ Department of Neurobiology, Civitan International Research Center, University of Alabama at Birmingham, Birmingham, Alabama 35294, and ${ }^{2}$ Program of \\ Developmental Neurobiology, Institute of Molecular Medicine and Genetics, Department of Neurology, Medical College of Georgia, Augusta, Georgia 30912
}

\begin{abstract}
Dysfunction of the ubiquitin proteasome system (UPS) has been implicated in the pathogenesis of many neurological diseases, including Alzheimer's, spinocerebellar ataxia, and several motor neuron diseases. Recent research indicates that changes in synaptic transmission may play a critical role in the progression of neurological disease; however, the mechanisms by which the UPS regulates synaptic structure and function have not been well characterized. In this report, we show that Usp14 is indispensable for synaptic development and function at neuromuscular junctions (NMJs). Usp14-deficient $a x^{J}$ mice display a resting tremor, a reduction in muscle mass, and notable hindlimb rigidity without any detectable loss of motor neurons. Instead, loss of Usp14 causes developmental defects at motor neuron endplates. Presynaptic defects include phosphorylated neurofilament accumulations, nerve terminal sprouting, and poor arborization of the motor nerve terminals, whereas postsynaptic acetylcholine receptors display immature plaque-like morphology. These structural changes in the NMJ correlated with ubiquitin loss in the spinal cord and sciatic nerve. Further studies demonstrated that the greatest loss of ubiquitin was found in synaptosomal fractions, suggesting that the endplate swellings may be caused by decreased protein turnover at the synapse. Transgenic restoration of Usp14 in the nervous system corrected the levels of monomeric ubiquitin in the motor neuron circuit and the defects that were observed in the motor endplates and muscles of the $a x^{J}$ mice. These data define a critical role for Usp 14 at mammalian synapses and suggest a requirement for local ubiquitin recycling by the proteasome to control the development and function of NMJs.
\end{abstract}

\section{Introduction}

Many pathways that are essential for the formation and function of the nervous system are regulated by the ubiquitin proteasome system (UPS). The UPS encodes hundreds of factors that specifically regulate protein degradation by the proteasome and effectively remove individual proteins from a complex cellular protein pool. This mechanism of targeted protein degradation is used for the control of numerous cellular processes including cell cycle progression, receptor signaling, and embryonic development.

The primary mechanism by which cells identify proteins for degradation by the UPS is by tagging them with a 76 aa protein called ubiquitin (Glickman and Ciechanover, 2002). The construction of a polyubiquitin chain of four or more ubiquitins effectively targets proteins to the proteasome (Thrower et al., 2000). Deubiquitinating enzymes act antagonistically to the ubiquitination reaction and cleave ubiquitin protein conjugates,

\section{Received June 5, 2009; revised July 6, 2009; accepted July 9, 2009}

This research was supported by the Evelyn F. McKnight Brain Institute, National Institutes of Health (NIH) Neuroscience Blueprint Core Grant NS057098 to the University of Alabama at Birmingham (UAB), NIH Grants NS040480 and NS056415 to L.M., and NIH-National Institute of Neurological Disorders and Stroke Grant NS047533 to S.M.W. We are grateful for NIH Grant P30NS47466 for tissue processing and staining, and we thank the UAB High Resolution Imaging Facility for help with confocal imaging and Edward Philips for help with tissue processing and staining of semithin sections. We also thank Drs. Michael Brenner and Gavin Rumbaugh for their helpful review of this manuscript.

Correspondence should be addressed to Scott M. Wilson at the above address. E-mail: Wilson@nrc.uab.edu. D0I:10.1523/JNEUROSCI.2635-09.2009

Copyright $\odot 2009$ Society for Neuroscience $\quad$ 0270-6474/09/2910909-11\$15.00/0 indicating that ubiquitin modification is a reversible process similar to protein phosphorylation. Central to the degradation of proteins by the proteasome is the cell's ability to properly maintain ubiquitin pools within different cellular compartments. Since the proteasome selects proteins for degradation based on the presence of a ubiquitin side chain, loss of ubiquitin pools would severely impair the ability of the proteasome to clear unwanted proteins from the cell and result in protein accumulation.

Neuronal development relies on the UPS for specialized steps such as neuronal migration and synaptogenesis (Yi and Ehlers, 2007), and defects in the UPS are associated with neurological disease (Alves-Rodrigues et al., 1998). For instance, loss of an E3 ligase causes Angelman syndrome, a neurodevelopmental disorder that results in ataxia and mental retardation (Kishino et al., 1997). X-linked infantile spinal muscular atrophy (XL-SMA) has been linked to changes in the E1 ubiquitin-activating enzyme (Ramser et al., 2008), implying that altered ubiquitination of motor neuron proteins may result in defective development of the motor unit. In support of this idea, mouse models of SMA have shown that the earliest signs of pathology occur at the neuromuscular junction (NMJ) (Kariya et al., 2008), indicating that defective maturation of the NMJ may be the initial insult that results in motor neuron disease in SMA patients.

Loss of the proteasomal deubiquitinating enzyme Usp14 in $a x^{J}$ mice (Wilson et al., 2002) results in underdevelopment of several regions of the CNS (D'Amato and Hicks, 1965). Usp14 is expressed during embryogenesis and in adult tissues, including 
the spinal cord and muscle (Wilson et al., 2002; Crimmins et al., 2009). Our previous work (Crimmins et al., 2006) showed that the tremor, hindlimb rigidity, and postnatal lethality in the $a x^{J}$ mice were not caused by the cerebellar pathology previously suggested by D'Amato and Hicks. The objective of this study was to identify the site of neurological dysfunction caused by loss of Usp14. We hypothesized that a defect in the motor neuron circuit was responsible for the severe neuromuscular phenotypes in the $a x^{J}$ mice. In this report, we demonstrate that the loss of Usp14 causes widespread changes in motor neuron endplates and developmental abnormalities at the NMJ that are consistent with impaired proteasome function at the synapse.

\section{Materials and Methods}

Animals. Wild-type (wt) C57BL/6J, Usp14 ${ }^{a x J}$, and Thy1-Yfp [Tg(Thy1YFP [yellow fluorescent protein])16Jrs] mice (Jackson Laboratories) have been maintained in our breeding colony at the University of Alabama at Birmingham, which is fully accredited by the Association for Assessment and Accreditation of Laboratory Animal Care International. Homozygous Usp $14^{a x J}$ mice (which we refer to as $a x^{J}$ mice) were generated by intercrossing $a x^{\mathrm{J}} /+$ siblings and could be phenotypically identified by 2 weeks of age. Transgenic Usp14 animals $\left(a x^{J}-T g\right)$ were generated as previously described (Crimmins et al., 2006) and were maintained on a C57BL/6J background. All research complied with the United States Animal Welfare Act and other federal statutes and regulations relating to animals and experiments involving animals and adhered to principles stated in the Guide for the Care and Use of Laboratory Animals, United States National Research Council.

Muscle wet weight analysis. Gastrocnemius muscles were collected from 2-, 4-, 6-, and 8-week-old wt, $a x^{J}$, and $a x^{J}-T g$ mice. Muscle weights were determined for six animals per genotype, and values are reported as the average muscle mass $\pm \mathrm{SE}$.

Muscle fiber analysis. Gastrocnemius muscles were collected from 4-week-old mice, weighed, and mounted cross-sectionally on cork in OTC medium mixed with tragacanth gum and frozen in liquid-nitrogencooled isopentane (Kim et al., 2005). All samples were stored at $-80^{\circ} \mathrm{C}$. Fiber analysis was conducted on four animals per genotype. Muscle mounts were cut in $6 \mu \mathrm{m}$ serial cross-sections at $-22^{\circ} \mathrm{C}$ using a Leica CM1900 cryostat microtome and placed on two-well slides (Erie Scientific). Slides were kept in a humidified chamber throughout the staining protocol. All applied solutions were removed by aspiration before administration of the succeeding solution. Sections were fixed for $45 \mathrm{~min}$ at room temperature in 3\% neutral-buffered formalin. After fixation, sections were washed two times for 5 min with $1 \times$ PBS. All subsequent PBS wash steps were three times for $5 \mathrm{~min}$. Sections were blocked with $5 \%$ goat serum in PBS for $20 \mathrm{~min}$ at room temperature followed by a wash step. Primary and secondary antibodies (Abs) were diluted in PBS containing $1 \%$ goat serum. Anti-major histocompatibility complex (MHC) type I primary $\mathrm{Ab}$ [mouse monoclonal $\mathrm{Ab}(\mathrm{mAb}) \mathrm{BA}-\mathrm{D} 5$, Developmental Studies Hybridoma Bank] was applied for $30 \mathrm{~min}$ at $37^{\circ} \mathrm{C}$. After a wash step, sections were incubated with Alexa Fluor 586-conjugated goat antimouse secondary $\mathrm{Ab}$ (Invitrogen) at a 1:500 dilution for $30 \mathrm{~min}$ at $37^{\circ} \mathrm{C}$. Sections were washed and again blocked in PBS containing 5\% goat serum for $20 \mathrm{~min}$ at room temperature. To locate sarcolemmae for myofiber sizing, a wash step was followed by incubation with anti-laminin mouse mAb VP-L551 (NovoCastra Laboratories) at a 1:80 dilution for 30 min at $37^{\circ} \mathrm{C}$, a wash step, and incubation with Alexa Fluor 488conjugated goat anti-mouse secondary Ab (Invitrogen) at a 1:500 dilution for $30 \mathrm{~min}$ at $37^{\circ} \mathrm{C}$. Slides were then washed and subjected to a third and final block in PBS containing 5\% goat serum for $20 \mathrm{~min}$ at room temperature. After a wash step, sections were incubated with the final primary $\mathrm{Ab}$ (anti-MHC type II mouse mAb My32, Sigma) at a 1:1000 dilution for $30 \mathrm{~min}$ at $37^{\circ} \mathrm{C}$, washed, and incubated with Alexa Fluor 488-conjugated goat anti-mouse secondary $\mathrm{Ab}$ at a 1:500 dilution for 30 min at $37^{\circ} \mathrm{C}$. Nuclei were revealed by a Hoechst 33258 DNA counterstain (Invitrogen) used at a 1:10,000 dilution in PBS for $2 \mathrm{~min}$ at room temperature. Slides underwent a final aspiration and were mounted with $1 \%$ paraphenylene diamine and 50\% glycerol in PBS. Slides and coverslips were bound together by use of clear nail polish and stored protected from light at $-20^{\circ} \mathrm{C}$. For cross-sectional measurements, 50 random type I and type II myofibers from each animal were manually traced along their laminin-stained border.

Quantitation of motor neuron and axon number. For quantitation of motor neuron numbers, transverse frozen sections of lumbar spinal cords (L4-L5) from 7-week-old wt and $a x^{J}$ mice were prepared and stained with cresyl violet as described by Blondet et al. (2002). Images from 10 sequential sections were collected and the area of motor neurons in the ventral horn was measured. For axon number quantitation, $0.5 \mu \mathrm{m}$ cross-sections from L4-L5 lumbar ventral roots were stained with toluidine blue ( $n=5$ mice per genotype). The sizes of both motor neurons and axons were measured by using NIS-Elements software (Nikon).

NMJ immunostaining and confocal imaging. For whole-mount immunostaining, mice were anesthetized with ketamine and xylazine $(n=6$ mice per developmental time point). Mice were then perfused with PBS, followed with $2 \%$ paraformaldehyde (PFA). Tibialis anterior, soleus, diaphragm, and sternomastoid muscles were dissected out and further fixed with 2\% PFA. Muscles were teased into fiber bundles and then washed with wash buffer (PBS containing 1\% Triton X-100) three times at room temperature for $15 \mathrm{~min}$. Muscle bundles were then blocked with $2 \%(\mathrm{w} / \mathrm{v}) \mathrm{BSA}$ and $4 \%$ goat serum in wash buffer for $1 \mathrm{~h}$. To label the acetylcholine receptors (AChRs), samples were incubated with $1 \mu \mathrm{g} / \mathrm{ml}$ $\alpha$-bungarotoxin-conjugated with tetramethylrhodamine isothiocyanate (TRITC) for $1 \mathrm{~h}$. After being washed three times at room temperature for 15 min with wash buffer, samples from Thy1-Yfp mice were mounted in PBS containing 50\% glycerol, and all other samples were incubated with primary $\mathrm{Abs}$ for $2 \mathrm{~d}$ at $4^{\circ} \mathrm{C}$. Primary Abs and their dilutions were as follows: neurofilament heavy chain, 1:400 (Sigma); neurofilament medium chain, 1:1000 (Sigma); synaptophysin, 1:400 (Millipore); SV2 synaptic vesicle proteins, 1:200 (Developmental Studies Hybridoma Bank); S100 protein, 1:200 (DAKO); phosphorylated neurofilaments SMI312, 1:400 (Covance); and Usp14, 1:200 (Crimmins et al., 2006). After being washed three times for $15 \mathrm{~min}$ at room temperature, samples were incubated with secondary Abs conjugated with Alexa Fluor 488, 568, or 643 dye (Invitrogen) at a 1:500 dilution for $1 \mathrm{~d}$ at $4^{\circ} \mathrm{C}$. For triple immunostaining, neurofilaments were labeled with anti-neurofilament medium chain and anti-neurofilament heavy chain, and synaptic vesicles were labeled with anti-synaptophysin. After being washed three times for 30 min at room temperature, samples were mounted in PBS containing 50\% glycerol and then stored at $-20^{\circ} \mathrm{C}$.

Quantitative PCR. Total RNA was isolated using RNA-STAT60 (TelTest), and $2 \mu \mathrm{g}$ of the RNA was then reverse transcribed using the Applied Biosystems GeneAmp Gold RNA PCR Reagent Kit. Real-time PCRs were set up in triplicate using TaqMan gene assays and amplified in an Applied Biosystems Step-One instrument. $\Delta \Delta$ CCT curves were generated using $18 \mathrm{~S}$ and GAPDH TaqMan gene assays as internal standards. Quantitative PCR (qPCR) results are shown as the SDs of three different amplifications from RNA that was reverse transcribed from three different mice. Individual gene assay kits were purchased from Applied Biosystems for each of the RNAs analyzed. Paired $t$ tests were conducted on relative quantity values for each group to determine their significance.

Electrophysiology. Intracellular electrophysiological recording was performed as previously described (Dong et al., 2006). Briefly, diaphragms with ribs and intact phrenic nerves were dissected from adult mice $(n=$ 6-8 mice per genotype), pinned on Sylgard gel (Ellsworth), and perfused at room temperature for at least $1 \mathrm{~h}$ with an oxygenated solution containing the following (in mM): $145 \mathrm{NaCl}, 5.4 \mathrm{KCl}, 1 \mathrm{MgCl}_{2}, 2 \mathrm{CaCl}_{2}, 10$ HEPES-NaOH, pH 7.3, and 13 glucose. Microelectrodes, 10-20 M $\Omega$ when filled with $3 \mathrm{M} \mathrm{KCl}$, were placed in the central region of the muscle fibers in which the AChR clusters were enriched. Positions were adjusted for maximal response with miniature endplate potentials (MEPPs). For recording of nerve-evoked endplate potentials (EPPs), phrenic nerves were sucked into an electrode and stimulated at $<1 \mathrm{~mA}$ for a pulse duration of $0.2 \mathrm{~ms}$. For all evoked recordings, $2 \mu \mathrm{M}$ mu-conotoxin GIIIB was used to block muscle contractions. The quantal content was calculated as the mean EPP amplitude/mean MEPP amplitude. Data were collected and analyzed using pClamp 9.2 software (Molecular Devices). 
A

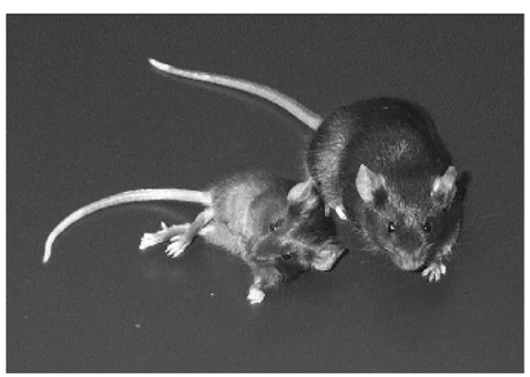

B

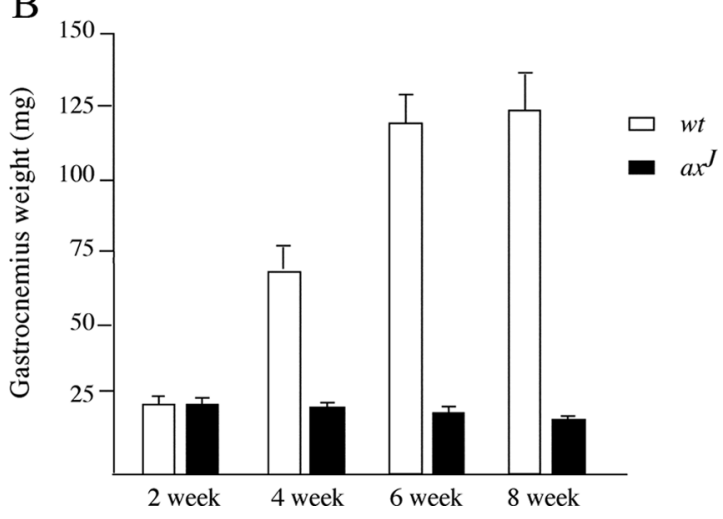

Figure 1. Altered muscle development in $a x^{\prime}$ mice. $A$, Six-week-old wt (right) and $a x^{\prime}$ (left) mice demonstrating the body mass difference and the extension and rigidity of the hindlimbs in the $a x^{J}$ mice. $\boldsymbol{B}$, Wet weights of gastrocnemius muscles from 2- to 8-week-old wt and $a x^{\prime}$ mice ( $n=6$ mice per time point).

Data are shown as mean \pm SEM, where ${ }^{\star}$ and ${ }^{\#}$ indicate $p<0.05$ and ** represents $p<0.01$.

Immunoblotting. Proteins were resolved on either $8 \%$ Tris-glycine gels or 4-20\% Tris-glycine NUPAGE gels (Invitrogen) and transferred onto PVDF membranes. The polyclonal Usp14 R138 antisera (Anderson et al., 2005) ubiquitin Mab1510 (Millipore), neurofilament heavy-chain $\mathrm{Ab}$ (Sigma) and anti- $\beta$-tubulin Ab (Developmental Studies Hybridoma Bank) were diluted in PBS containing 3\% BSA. Primary Abs were detected using an anti-mouse or anti-rabbit HRP-conjugated secondary $\mathrm{Ab}$ (Southern Biotechnology Associates) and luminol reagents (Pierce).

Quantitation of immunoblots. Blots were scanned using a HewlettPackard Scanjet 3970 and quantitated using UN-SCAN-IT software (Silk Scientific). Each value represents the average and SE from four blots using at least three different animals of each genotype.

Synaptosome preparation. Synaptosomes were prepared as described by Dodd et al. (1981). Briefly, brains were removed and homogenized in $7 \mathrm{ml}$ of ice-cold buffer containing $0.32 \mathrm{~m}$ sucrose, $5 \mathrm{~mm}$ HEPES, $\mathrm{pH}$ 7.4, and protease inhibitor mixture $(n=4$ mice per genotype). The homogenate was then centrifuged at $1700 \times g$ for $15 \mathrm{~min}$ at $4^{\circ} \mathrm{C}$. The supernatant was layered over a $1.2 \mathrm{M}$ sucrose cushion and centrifuged at 105,000 $\times \mathrm{g}$ for $30 \mathrm{~min}$ at $4^{\circ} \mathrm{C}$. A protein fraction at the $0.32-1.2 \mathrm{M}$ interface was collected and resuspended in $7 \mathrm{ml}$ of $0.32 \mathrm{M}$ sucrose. This suspension was then layered over a $0.8 \mathrm{M}$ sucrose cushion and centrifuged at $130,000 \times g$. The resulting pellet was resuspended in RIPA buffer.

\section{Results}

$a x^{J}$ mice have altered muscle development

The $a x^{J}$ mice were given the name "ataxia" because of the movement disorders and cerebellar defects observed during postnatal development (Lyon, 1955). However, our studies on the $a x^{J}$ mice have indicated that the Purkinje cell axonal swellings in the cerebellum (D'Amato and Hicks, 1965) are not the primary cause of the observed motor deficits in these mice (Crimmins et al., 2006). By 4-5 weeks of age, the hindlimbs of the $a x^{J}$ mice become inflexible (Fig. $1 \mathrm{~A}$ ) and the mice rely mainly on their forelimbs for mobility. Although there is no difference in brain weight between wt and $a x^{J}$ mice at $4-5$ weeks of age (Anderson et al., 2005), the $a x^{J}$ mice have a significant reduction in body mass compared with controls (Fig. 1A). To determine whether muscle mass is also reduced by the loss of Usp14, we compared the weights of gastrocnemius muscles from wt and $a x^{J}$ mice during the first 8 weeks of postnatal development. At 2 weeks of age, the gastrocnemius muscle weights from the $a x^{J}$ mice were indistinguishable from those of their littermate controls (Fig. 1B). However, by 4 weeks of age, the gastrocnemius muscle weights of the $a x^{J}$ mice were $<60 \%$ of the controls. Although the gastrocnemius muscle weights of the control mice continued to increase during the first 6 weeks of postnatal development, the gastrocnemius muscle weights of the $a x^{J}$ mice showed no increase after 2 weeks of age (Fig. $1 \mathrm{~B}$ ). Similar results were observed for the tibialis anterior muscles (data not shown).

To determine whether the reduced muscle weights were caused by a specific effect on either type I or type II muscle fibers in the $a x^{J}$ mice, gastrocnemius muscles from wt and $a x^{J}$ mice were sectioned and stained with antibodies specific for either type I or type II muscle fibers. At 4 weeks, there was a $40 \%$ reduction in the cross-sectional area of the type I fibers (700 vs $\left.1120 \mu \mathrm{m}^{2}\right)$ and a $52 \%$ reduction in the size of the type II fibers ( 685 vs $1410 \mu \mathrm{m}^{2}$ ) in the $a x^{J}$ mice compared with controls, suggesting that the muscles in the $a x^{J}$ mice may lack sufficient motor neuron input for normal fiber development and growth. Unlike some mouse models of motor neuron disease, no fiber type grouping or increase in centrally located nuclei was observed in the $a x^{J}$ muscles compared with controls (data not shown).

Loss of Usp14 causes abnormal expression of AChR subunits The AChR is a pentameric protein complex composed of five subunits of either $\alpha_{2} \beta \gamma \delta$ or $\alpha_{2} \beta \varepsilon \delta$ and is responsible for detecting acetylcholine released by motor neurons at the NMJ. Changes in AChR mRNA subunit expression have been observed during postnatal development and after nerve damage. For example, subunit switching from the $\gamma$ subunit to the $\varepsilon$ subunit occurs during postnatal development (Mishina et al., 1986) and denervated skeletal muscles undergo atrophy and exhibit increased expression of both embryonic and adult AChR mRNAs (Goldman et al., 1988; Adams et al., 1995). To determine whether AChR mRNA expression in the $a x^{J}$ mice resembles that observed after muscle denervation, we performed qPCR on RNA isolated from the tibialis anterior muscles of wt and $a x^{J}$ mice at postnatal day 0 (P0), P7, P14, and P28. In both wt and $a x^{J}$ mice, the level of the AChR $\gamma$ subunit mRNA was downregulated (Fig. $2 A$ ) and the $\varepsilon$ subunit mRNA increased (Fig. $2 B$ ) during the first 2 weeks of postnatal growth. Whereas the patterns of expression of all five AChR subunit mRNAs in the $a x^{J}$ and wt mice were similar during the first 2 weeks of postnatal development, the mRNA levels of all five AChR subunits were highly elevated in 4-week-old $a x^{J}$ mice compared with controls (Fig. 2A-E). The loss of Usp14 therefore results in the upregulation of AChR expression in the $a x^{J}$ mice in a manner that is similar to that seen in denervated muscles.

\section{Characterization of the motor neuron circuit in $a x^{J}$ mice}

To determine whether the $a x^{J}$ movement disorder was caused by a defect in the motor neuron circuit, we first compared the numbers and sizes of the motor neurons in the ventral horn of the lumbar segments that innervate the hindlimbs from the spinal cords of 7-week-old wt and $a x^{J}$ mice, a time point that is close to the death of $a x^{J}$ mice. No significant differences were detected in activated caspase-3 staining (data not shown) or the total number 

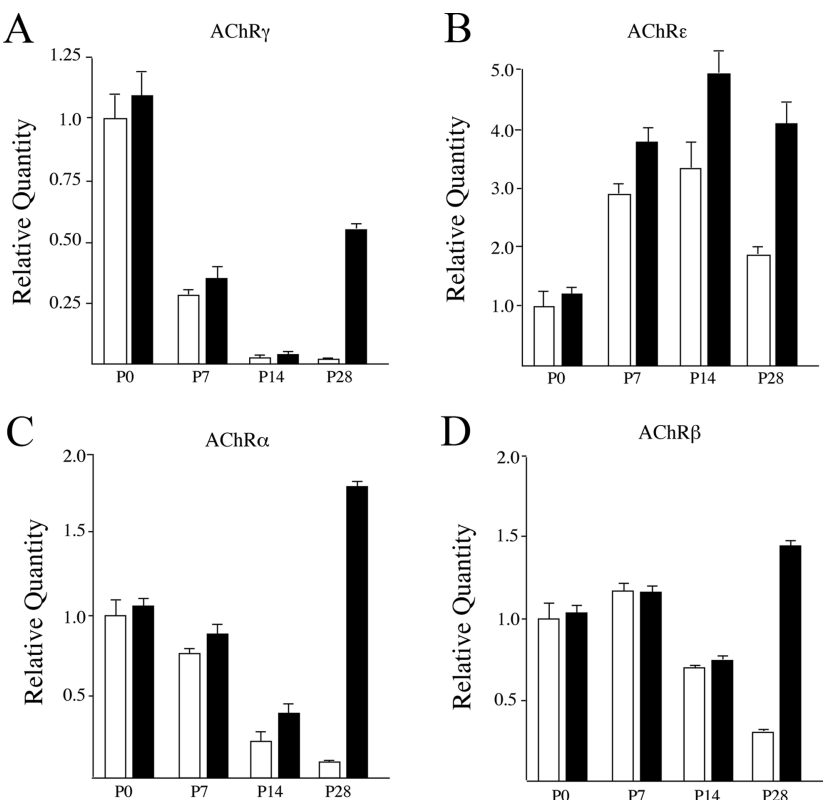

$\mathrm{D}$

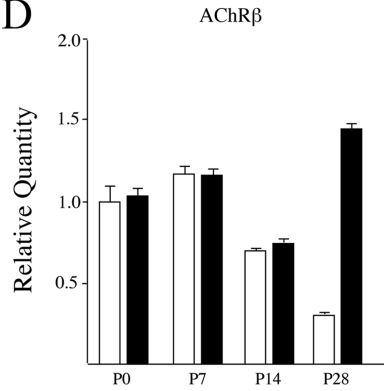

$\mathrm{E}$

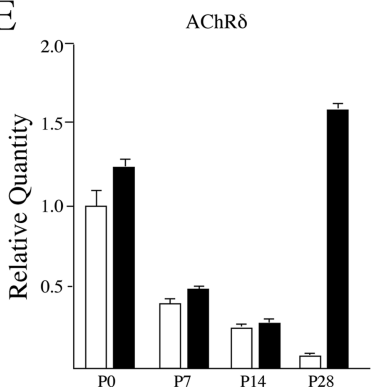

Figure 2. Loss of Usp14 results in increased levels of AChR subunit mRNAs. $A-E$, Quantitative PCR of $A C h R \gamma(\boldsymbol{A}), \operatorname{AChR} \varepsilon(\boldsymbol{B}), A C h R \alpha(\boldsymbol{C}), \operatorname{AChR} \beta(\boldsymbol{D})$, and $A C h R \delta(\boldsymbol{E}) \mathrm{mRNA}$ from the tibialis anterior muscles of wt (white bars) and $a x^{\prime}$ (black bars) mice during the first 4 weeks of postnatal development. Data are shown as mean $\pm \mathrm{SE}$, where $n=3$ mice per genotype.

of motor neurons in the L4 and L5 segments between $a x^{J}$ mice and wt controls (wt, $80 \pm 15 ; a x^{J}, 85 \pm 10$ ). However, there was a reduction in the number of large motor neurons $\left(>400 \mu \mathrm{m}^{2}\right)$ in the $a x^{J}$ mice compared with controls (Fig. $3 A$ ), indicating that the loss of Usp14 may affect the development, but not the survival, of the motor neurons.

To determine whether the decreased muscle mass in the $a x^{J}$ mice was caused by axonal loss, semithin sections of lumbar ventral roots from $a x^{J}$ and wt control mice were stained with toluidine blue (Fig. 3B). This analysis of L4-L5 ventral roots demonstrated that there were significantly more smaller axons with a diameter of $\sim 3 \mu \mathrm{m}$ in the $a x^{J}$ mice (Fig. $3 C$ ) than in the controls (wt $=40.7 \pm 7, n=4 ; a x^{J}=58.7 \pm 3.8, n=4 ; p=$ 0.004 ), indicating that Usp14 may contribute to axonal growth and development. There was no significant difference in the total number of L4-L5 axons between the $a x^{J}$ and wt mice.

Our previous studies demonstrated that the $a x^{J}$ mice have altered synaptic transmission at diaphragm NMJs (Wilson et al., 2002). To determine whether structural changes may contribute to the synaptic deficits at the $a x^{J}$ NMJ, we performed immunohistochemistry on the tibialis anterior, soleus, diaphragm, and sternomastoid muscles of 3-week-old wt and $a x^{J}$ mice that contained a transgene that expressed yellow fluorescent protein in motor neurons (Thy1-Yfp) (Feng et al., 2000). Presynaptic axons and nerve terminals were visualized by immunofluorescence from the Thy1-Yfp transgene, and the distribution of postsynaptic AChRs was determined by staining with TRITC- $\alpha$-bungarotoxin. The motor axon terminals from wt muscles were highly branched and juxtaposed the staining of the AChRs (Fig. 4). These highly branched endplates resembled the typical "pretzel-like" structures that have been reported previously (Sanes and Lichtman, 2001). In contrast, all of the NMJs from the tibialis anterior muscles of the $a x^{J}$ mice were abnormal (Fig. 4). Approximately ninety-two percent of these NMJs displayed nerve terminal swellings, where $33 \%$ had swollen and poorly arborized nerve terminals and 59\% also exhibited nerve terminal sprouting. Approximately eight percent of the endplates were not innervated, indicating possible muscle denervation in the $a x^{J}$ mice. In addition, the postsynaptic AChRs of the $a x^{J}$ terminals were not arrayed in the standard pretzel-like shape and were less perforated, indicating a lack of postsynaptic maturation in the $a x^{J}$ mice (Fig. 4). The soleus and sternomastoid muscles of the $a x^{J}$ mice exhibited NMJ defects that were similar to those observed in the tibialis anterior muscles (Fig. 4).

In contrast to the hindlimb and neck muscles of the $a x^{J}$ mice, in which all of the NMJs were structurally abnormal, 54\% of the nerve terminals in the diaphragms of the $a x^{J}$ mice were branched and showed no signs of NMJ pathology. However, 27\% of the NMJs from the diaphragms of the $a x^{J}$ mice still had swollen and poorly arborized terminals, $17 \%$ exhibited ultraterminal sproutings, and $2 \%$ had vacant endplates (Fig. 4). No abnormal terminals were observed in diaphragms of wt mice. These results indicate that there was a differential sensitivity of NMJs to the loss of Usp14 in the $a x^{J}$ mice.

\section{Loss of Usp14 affects the development of the NMJ}

Since loss of Usp14 resulted in several structural changes to the $\mathrm{NMJ}$ that are consistent with an NMJ developmental defect in the $a x^{J}$ mice, we examined motor endplate morphology in the tibialis anterior muscles of wt and $a x^{J}$ mice from P7 to P35 to determine whether NMJ development was impaired because of the loss of Usp14. Motor nerve terminals from wt mice expressing the Thy1Yfp transgene began to show signs of terminal differentiation and arborization of AChRs by P7 (Fig. 5), which is one of the first time points at which we can detect the expression of Yfp from the transgene. By P14, the motor terminals in the wt mice were branched and the AChRs were acquiring a pretzel-like structure. Fully mature and highly branched nerve terminals that completely overlap the mature pretzel-like AChRs were observed in the control mice by $\mathrm{P} 21$. In contrast, at P7, the presynaptic nerve terminals from the $a x^{J}$ mice containing the Thyl-Yfp transgene exhibited multiple nerve terminal sproutings that did not oppose an AChR cluster (Fig. 5). From P14 to P21, most of the presynaptic nerve terminals that opposed an AChR cluster displayed swollen nerve terminals and were also poorly arborized in the $a x^{J}$ mice. By P35, the $a x^{J}$ nerve terminals displayed large swellings as well as terminals that were partially innervated. The postsynaptic AChRs in the $a x^{J}$ mice at P14 and P21 were also significantly less perforated than controls (Fig. 5). These results suggest that Usp14 is required for the development of both the presynaptic and the postsynaptic components of the NMJ.

\section{$a x^{J}$ motor endplate swellings contain neurofilaments}

Changes in neurofilament distribution are characteristic of degenerating motor neurons from patients with motor neuron dis- 
A
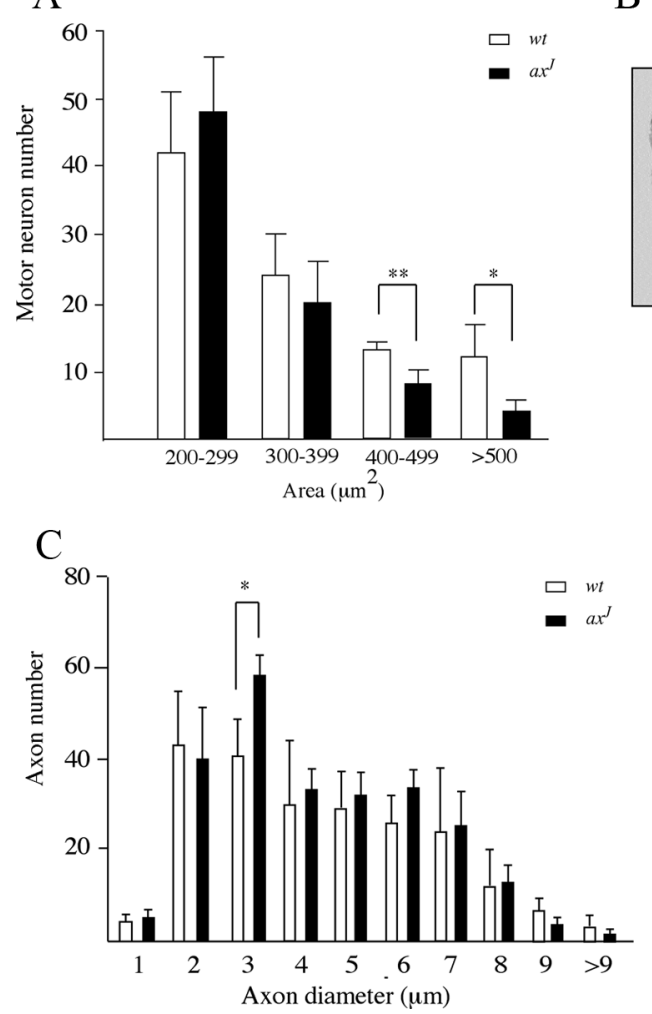

Figure 3. Analysis of the motor neuron circuit in 7-week-old wt and $a x^{\prime}$ mice. $A$, Relative frequency distribution of motor neuron cell soma size, indicating a reduction of larger motor neurons in $a x^{\prime}$ mice. $B$, Semithin sections of $L 4-L 5$ ventral root axons from $a x^{\prime}$ and wt control mice stained with toluidine blue. Scale bar, $20 \mu \mathrm{m}$. C, Relative frequency distribution of axon size in $L 4-L 5$ ventral roots ( $n=4$ mice per genotype). Student's $t$ test; ${ }^{*} p<0.05 ;{ }^{* *} p<0.01$.

B

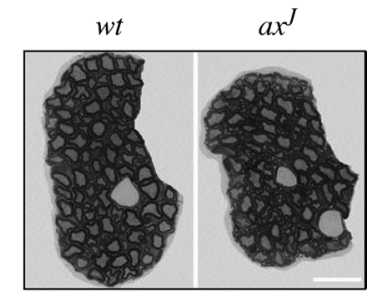

$a x^{\prime}$

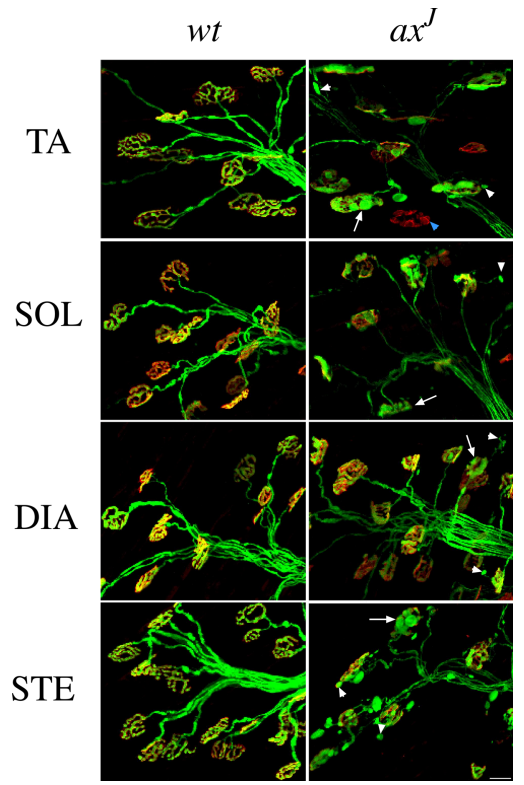

Figure 4. Motor endplate pathology in 3-week-old $a x^{\prime}$ mice. Muscle fibers from wt and $a x^{\prime}$ mice containing the Thy $1-Y f p$ transgene were stained with TRITC- $\alpha$-bungarotoxin (red) to label the postsynaptic AChR. The presynaptic axons and nerve terminals were visualized by fluorescence from the Yfp transgene (green). Arrow, Swollen presynaptic terminal apposed to AChRs; arrowhead, nerve terminal sprouting; blue arrowhead, vacant endplate. TA, Tibialis anterior; SOL, soleus; DIA, diaphragm; STE, sternomastoid muscle. Scale bar, $20 \mu \mathrm{m}$. orders like amyotropic lateral sclerosis and spinal muscular atrophy (Kondo et al., 1986; Cifuentes-Diaz et al., 2002; Kariya et al., 2008; Murray et al., 2008; Kong et al., 2009). Neurofilament overexpression also leads to aggregation of neurofilaments and motor neuron dysfunction in mice (Lee et al., 1992; Côté et al., 1993; Xu et al., 1993; Collard et al., 1995; Tu et al., 1995; Gama Sosa et al., 2003). To determine whether loss of Usp14 results in alterations in neurofilament distribution in the $a x^{J}$ mice, motor endplates from $\mathrm{P} 1$, $\mathrm{P} 7$, and P14 wt and $a x^{J}$ mice were examined by staining tibialis anterior muscles with phosphorylated neurofilament and synaptic vesicle antibodies. Comparison of the staining patterns from P1 mice did not demonstrate any major changes in the development of the motor endplates in the tibialis anterior muscles of the $a x^{J}$ mice compared with controls (Fig. 6). In wt P7 mice, phosphorylated neurofilaments were restricted to the axons and the most proximal parts of the axon terminals (Fig. 6). In the $a x^{J}$ mice, phosphorylated neurofilaments accumulated in focal swellings at $\mathrm{P} 7$ axon terminals, in the same areas in which swellings were seen in the images from $a x^{J}$ mice containing the Thy1-Yfp transgene (Fig. 5). These results indicate that loss of Usp14 results in a developmental defect in the NMJ, and alterations in the cytoskeletal structure may therefore contribute to the disease process in the $a x^{J}$ mice.

Expression of Usp14 from a Thy1-Usp14 transgene corrects the muscle and motor endplate defects of the $a x^{J}$ mice Our previous studies demonstrated that neuronal expression of Usp14 by a Thy 1-Usp14 (Tg) transgene restores viability to the $a x^{J}$ mice (Crimmins et al., 2006). We therefore investigated muscle size and AChR expression in the $a x^{J}-T g$ mice to determine whether the transgene could also correct the muscle defects that were observed in the $a x^{J}$ mice. Comparison of gastrocnemius muscle wet weights and muscle fiber sizes from 4-week-old wt, $a x^{J}$, and $a x^{J}-T g$ mice demonstrated that the Thy1-Usp14 transgene was sufficient to restore wt muscle weights and muscle fiber size to the gastrocnemius muscles of the $a x^{J}$ mice (supplemental Fig. 1, available at www.jneurosci.org as supplemental material). When we compared the expression of the AChR $\alpha$ and $\beta$ subunits in the wt, $a x^{J}$, and $a x^{J}-T g$ mice, we found that the Thy1-Usp14 transgene also restored expression of these AChR subunits back to wt levels (supplemental Fig. 1, available at www.jneurosci.org as supplemental material), indicating that the changes observed in the $a x^{J}$ muscles were caused by the neuronal loss of Usp14.

To determine whether neuronal expression of Usp14 could rescue the anatomical NMJ deficits in the $a x^{J}$ mice, we examined the NMJ structure in wt mice, $a x^{J}$ mice, and $a x^{J}-T g$ mice, which also contained the Thyl-Yfp transgene. In contrast to the $a x^{J}$ mice, in which almost all of the endplates found on the tibialis anterior muscles were abnormal, the NMJs of the $a x^{J}-T g$ mice were well branched and without any signs of nerve terminal sproutings or swellings (Fig. 7A; supplemental Fig. 2, available at 


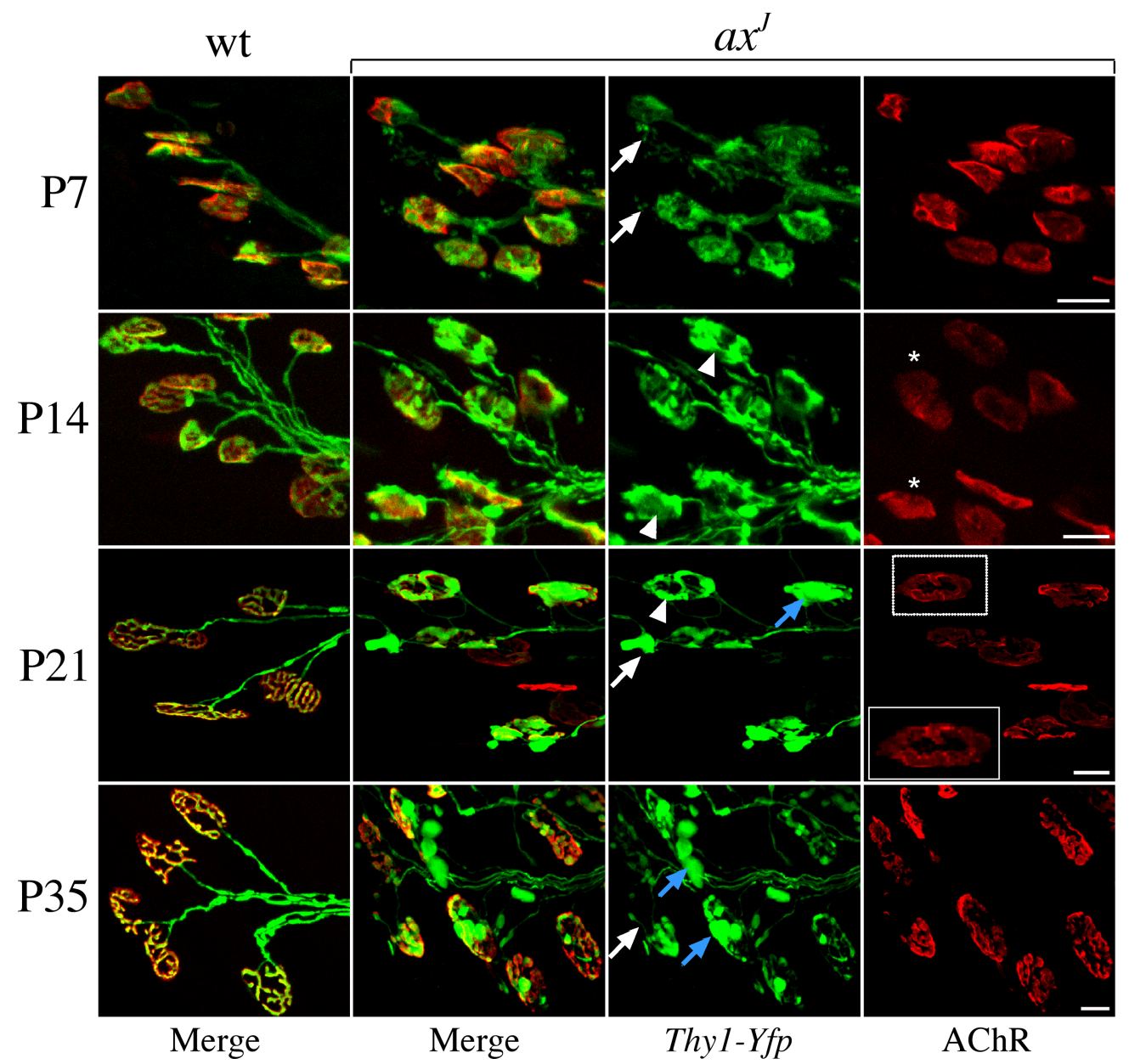

Figure 5. Loss of Usp14 in ax ${ }^{\prime}$ mice results in NMJ developmental deficits. Tibialis anterior muscles were prepared from wt and ax ${ }^{\prime}$ mice containing the Thy 1-Yfp transgene at P7, P14, P21, and P35. Presynaptic axons and nerve terminals were visualized by fluorescence from the Yfp transgene (green), and postsynaptic endplates were stained with TRITC- $\alpha$-bungarotoxin (red). Arrows, Nerve terminal sprouting that does not oppose any detectable AChRs; arrowhead, nerve terminals with poor arborization; blue arrow, nerve terminal swelling; asterisk, plaque-like AChRs. Boxed regions demonstrate immature AChRs with one perforation. Scale bar, $20 \mu \mathrm{m}$.

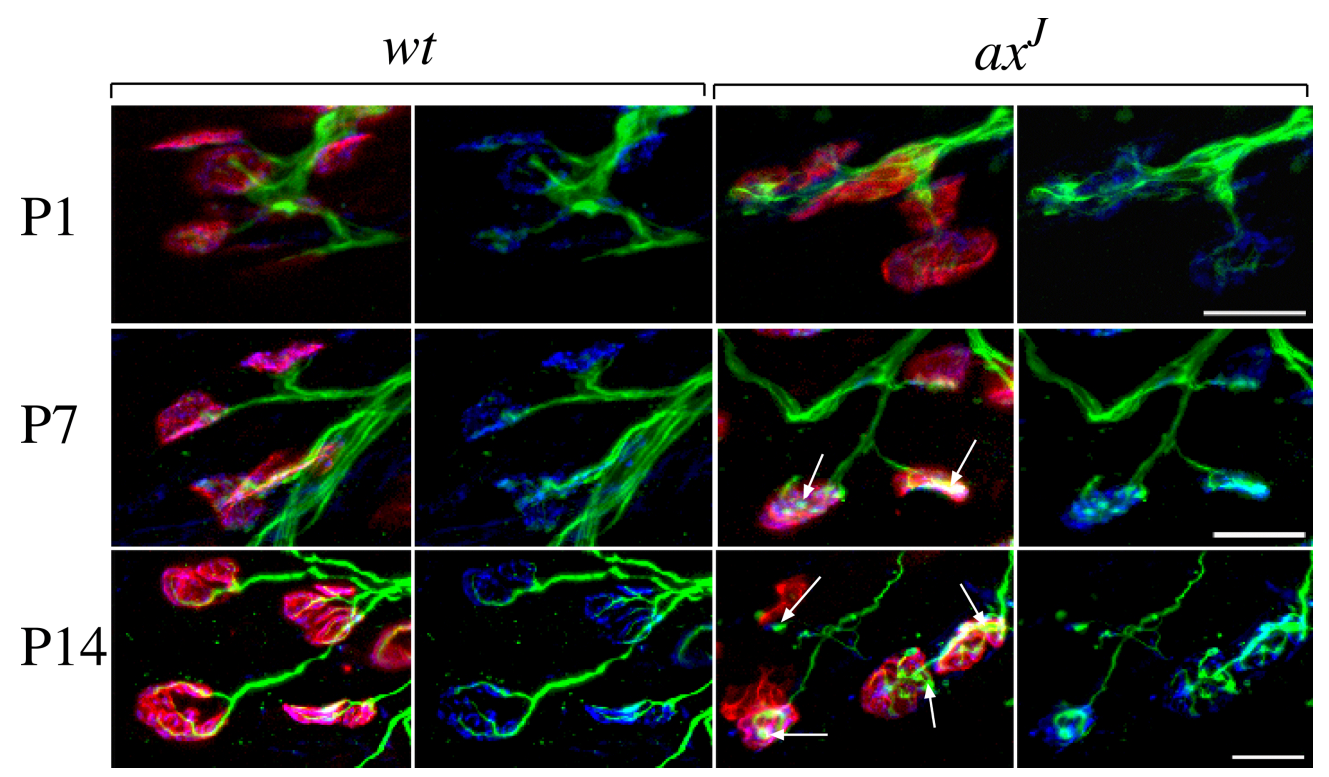

Figure 6. Loss of Usp14 results in neurofilament accumulation at NMJs during postnatal development. Whole-mount immunostaining of tibialis anterior muscles from P1, P7, and P14 wt and ax' mice. Muscles were stained with antibodies for neurofilaments (green) or SV2 synaptic vesicle protein (blue), or with TRITC- $\alpha$-bungarotoxin to stain AChRs (red). Arrows indicate neurofilament accumulation at the NMJ. Scale bar, $20 \mu \mathrm{m}$. 
A

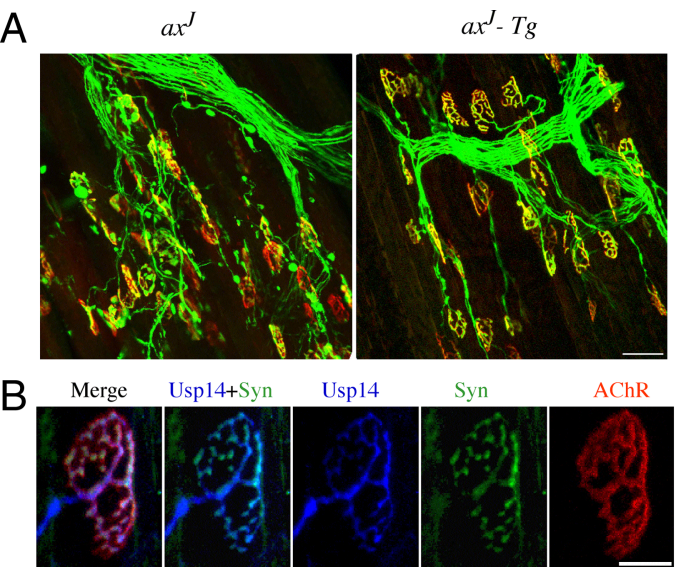

C

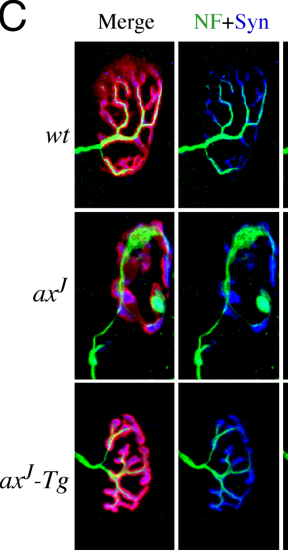

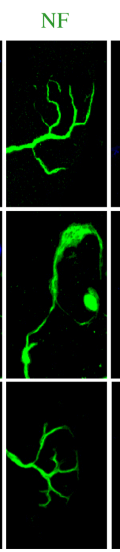

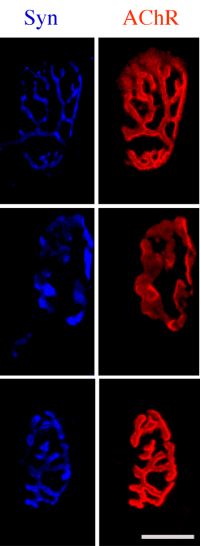

Figure 7. Neuronal expression of Usp14 rescues the NMJ pathologies in $a x^{\prime}$ mice. A, Whole-mount immunostaining of tibialis anterior muscles from P35 ax and transgenic $a x^{\prime}-T^{\prime}$ Thy $1-U s p 14$ $\left(a x^{\prime}-T g\right)$ mice containing the Thy1-Yfp transgene. Nerve terminals were visualized by immunofluorescence from the Thy 1-Yfp transgene (green), and postsynaptic endplates were stained with TRITC- $\alpha$-bungarotoxin (red). Scale bar, $50 \mu \mathrm{m}$. B, Representative NMJs from tibialis anterior muscles of P35 ax'-Tg mice stained with antibodies to synaptophysin (Syn; green), Usp14 (blue), and AChR (red). Scale bar, $20 \mu \mathrm{m}$. C, Tibialis anterior muscles from P35 wt, $a x^{\prime}$, and $a x^{\prime}-\mathrm{Tg}$ mice stained with TRITC- $\alpha$-bungarotoxin (red) or with antibodies for neurofilament (NF; green) or synaptophysin (blue). Scale bar, $20 \mu \mathrm{m} . n=6$ mice per genotype.

A $w t$ $a x^{J}$ $a x^{J}-T g$
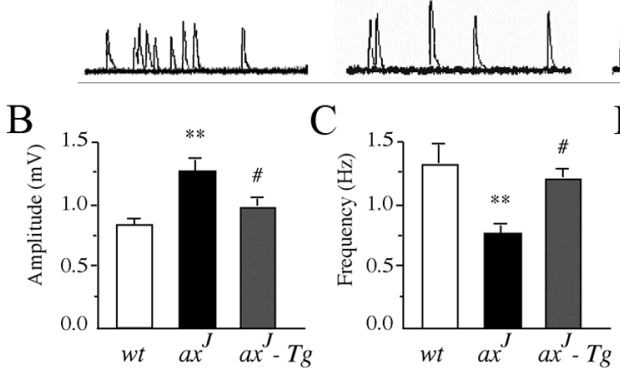

$\mathrm{E}$

\begin{tabular}{lcccccc}
\hline \multirow{2}{*}{ Mice } & \multicolumn{2}{c}{ Amplitude $(\mathrm{mV})$} & \multicolumn{2}{c}{ Frequency $(\mathrm{Hz})$} & \multicolumn{2}{c}{ Membrane Potential (mV) } \\
& Mean & SEM & Mean & SEM & Mean & SEM \\
\hline \multirow{2}{*}{$w t$} & 0.821 & 0.07 & 1.30 & 0.16 & -72.65 & 9.30 \\
$a x^{J}$ & 1.261 & 0.11 & 0.79 & 0.08 & -70.27 & 10.84 \\
$a x^{J}-T g$ & 0.971 & 0.09 & 1.15 & 0.11 & -70.97 & 8.43 \\
\hline
\end{tabular}

F

wt $a x^{J} \quad a x^{I}-T g$

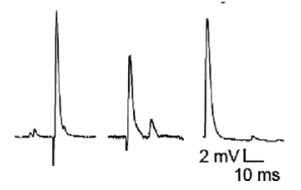

G

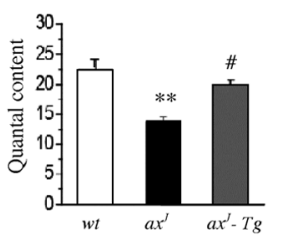

$\mathrm{H}$

\begin{tabular}{lcc}
\hline & \multicolumn{2}{c}{ Quantal content } \\
Mice & Mean & SEM \\
\hline$w t$ & 22.4 & 1.7 \\
$a x^{J}$ & 13.7 & 0.9 \\
$a x^{J}-T g$ & 19.1 & 1.6 \\
\hline
\end{tabular}

Figure 8. Thy 1-Usp14 rescues the NMJ synaptic transmission defects in 5-week-old $a x^{J}$ mice. $A$, Representative traces of MEPPs from diaphragm NMJs from wt, $a x^{\prime}$, and $a x^{\prime}-T g$ mice. $\boldsymbol{B}-\boldsymbol{D}$, MEPP amplitude $(\boldsymbol{B})$, MEPP frequency $(\boldsymbol{C})$, and resting membrane potentials (D) from wt, $a x^{\prime}$, and $a x^{\prime}-T g$ mice. $E$, Summary of MEPP data. $\boldsymbol{F}$, EPC traces from diaphragms of wt, $a x^{\prime}$, and $a x^{\prime}-\operatorname{Tg}$ mice. G, Quantal content deficiencies in $a x^{\prime}$ mice are corrected by the Thy 1 -Usp 14 transgene. $\boldsymbol{H}$, Summary of quantal content data from $w t, a x^{\prime}$, and $a x^{\prime}-T g$ mice. Data were generated from six to eight animals per genotype and are shown as mean \pm SEM. Student's $t$ test: ${ }^{* *} p<0.01$ (values compared with wt samples), ${ }^{*} p<0.05$ (values compared with $a x^{\prime}$ samples).

www.jneurosci.org as supplemental material). To confirm that the Thy1-Usp14 transgene expressed Usp14 in motor neurons, NMJs from the tibialis anterior muscles of $a x^{J}-T g$ mice were immunostained for Usp 14. The $a x^{J}$ - Tg mice expressed high levels of Usp14 throughout the cell body, the axon, and the nerve terminals (Fig. 7B; data not shown). As expected, no Usp14 was detected in the muscles of the $a x^{J}$ - $T g$ mice (see Fig. 9C). Usp14 was also found to colocalize with synaptophysin, indicating that Usp14 could directly act at the presynaptic compartment to correct the structural defects at the $a x^{J}$ NMJs.

To investigate whether the neuronal expression of Usp14 also corrected both the presynaptic neurofilament accumulation and decreased perforation of the muscle AChRs, we examined the distribution of neurofilaments, synaptophysin, and AChRs in wt, $a x^{J}$, and $a x^{J}-T g$ mice by immunostaining. All of the presynaptic abnormalities and the impaired branching of AChRs in the $a x^{J}$ mice were corrected by neuronal expression of the Thy1-Usp14 transgene (Fig. $7 C$ ). These results suggest that Usp14 is required for the development of motor endplates and that the neurological deficits in the $a x^{J}$ mice are caused by changes in motor neuron function.

The Thy1-Usp14 transgene rescues the synaptic transmission defects at the NMJs of $a x^{J}$ mice

In addition to the structural abnormalities described in this report, we previously observed changes in synaptic function in the NMJs from the diaphragm muscles of the $a x^{J}$ mice, which included a decreased frequency and an increased amplitude of spontaneous neurotransmitter release, as well as a reduction in quantal content (Wilson et al., 2002). We therefore investigated whether neuronal restoration of Usp14 would correct the synaptic alterations observed in the $a x^{J}$ mice. To examine synaptic transmission at the NMJs, spontaneous and evoked release of neurotransmitter was measured from the diaphragms of 4- to 6-week-old wt, $a x^{J}$, and $a x^{J}-T g$ mice. Consistent with our previous findings (Wilson et al., 2002), MEPPs from $a x^{J}$ mice showed a $40 \%$ reduction in frequency and a 1.5 -fold increase in ampli- 
tude compared with wt controls (Fig. 8A,B). A 1.5-fold increase in miniature endplate currents was also observed in the $a x^{J}$ mice, which is consistent with our previous studies (Wilson et al., 2002). Restoration of Usp14 expression in the motor neurons of the $a x^{J}-T g$ mice corrected both the mini-frequency and amplitude defects seen in the $a x^{J}$ mice to near wild-type levels (Fig. 8A-E).

To determine whether the Thy1-Usp14 transgene also corrected the deficiency in neurotransmitter release that was observed in the $a x^{J}$ mice, we first examined EPPs of the NMJs from the diaphragms of 4- to 6-week-old wt, $a x^{J}$, and $a x^{J}$ - $T g$ mice. Similar to what we previously reported (Wilson et al., 2002), the EPC amplitudes of the $a x^{J}$ mice were reduced 30\% compared with controls (Fig. 8 F). The increase in miniature endplate currents and decreased EPPs in the $a x^{J}$ mice corresponded to a $40 \%$ reduction in quantal content compared with controls (Fig. $8 G, H)$. Expression of the Thy1-Usp14 transgene in the $a x^{J}-T g$ mice corrected the EPP amplitudes and restored quantal content to near-wt levels (Fig. 8G,H). No significant differences in synaptic transmission were observed between the wt and $a x^{J}-T g$ mice. These results indicate that Usp14 is required for both synaptic function and the normal development of NMJs.

\section{Loss of ubiquitin in axons of $a x^{J}$ mice}

Changes in ubiquitin homeostasis are thought to disrupt many cellular pathways, and ubiquitin loss has been observed in a few cases of neurological disease (Osaka et al., 2003; Anderson et al., 2005; Walters et al., 2008). Since some models of motor neuron disease have indicated that changes in axonal properties occur before any measurable loss of motor neuron cell bodies (De Vos et al., 2008), we investigated the possibility that Usp14 functions to stabilize the ubiquitin pools found in the motor neuron axons. Protein extracts were isolated from the spinal cords and sciatic nerves of 4-week-old wt, $a x^{J}$, and $a x^{J}$-Tg mice and examined for the levels of free and conjugated ubiquitin. We observed a $30 \%$ reduction in the level of monomeric ubiquitin in the spinal cords and muscle extracts and a $40 \%$ reduction of monomeric ubiquitin in sciatic nerve extracts from the $a x^{J}$ mice compared with controls (Fig. 9A-C) without any corresponding change in the level of conjugated ubiquitin. Loss of Usp14 did not appear to affect the steady-state neurofilament heavy-chain levels in the spinal cords or sciatic nerves of the $a x^{J}$ mice (Fig. 9A,B), and no significant accumulation of neurofilament heavy chain was detected in the ventral horn motor neurons of the $a x^{J}$ mice by immunohistochemistry (data not shown). Analysis of spinal cord and sciatic nerve extracts from the $a x^{J}$ - Tg mice demonstrated that transgenic expression of Usp14 restored monomeric ubiquitin levels back to wt levels (Fig. 9A,B), indicating that Usp14 is required for the maintenance of monomeric ubiquitin in the spinal cord and motor neuron axons. Although the Thy1-Usp14 transgene was not expressed in the tibialis anterior muscles, the ubiquitin levels were also restored in the muscles of the $a x^{J}-T g$ mice (Fig. 9C), suggesting that ubiquitin expression in muscles can be modulated by changes in nervous system activity and/or function.

\section{Decreased synaptic ubiquitin in $a x^{J}$ mice}

Ubiquitin is thought to be translated in the cell soma and transported down axons via slow component B (Bizzi et al., 1991). Since localized accumulations of neurofilament at the NMJ synapses in the $a x^{J}$ mice suggest that ubiquitin recycling by the proteasome may be insufficient to maintain ubiquitin levels and efficient protein degradation at synaptic sites, we investigated the
A
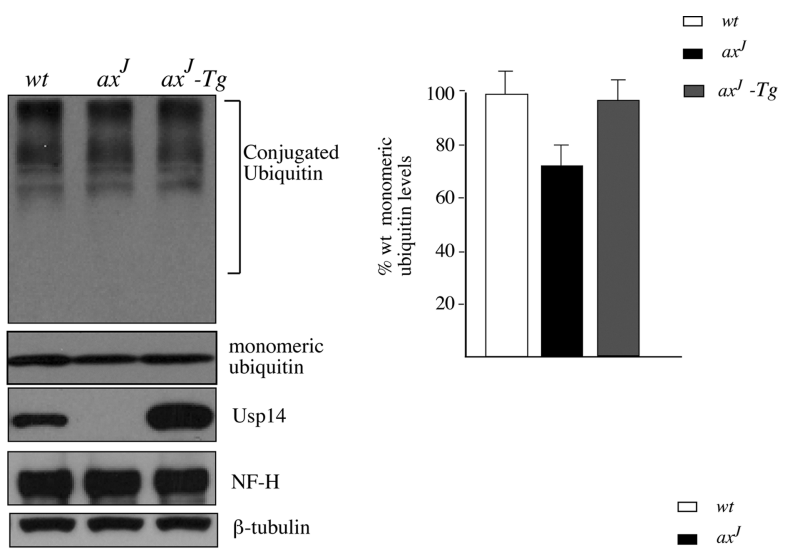

B
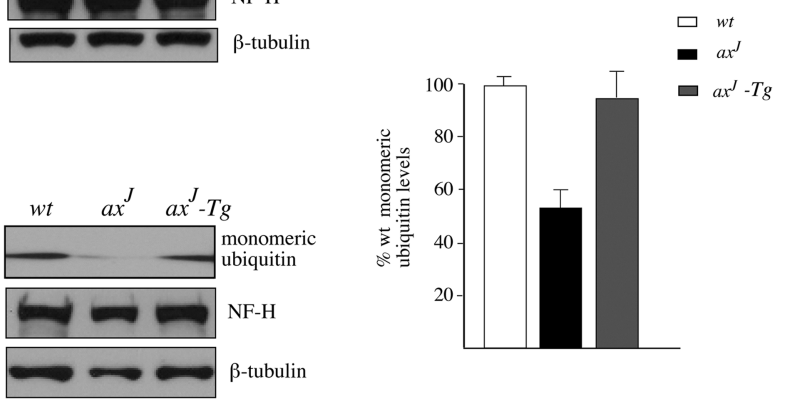

$\mathrm{C}$
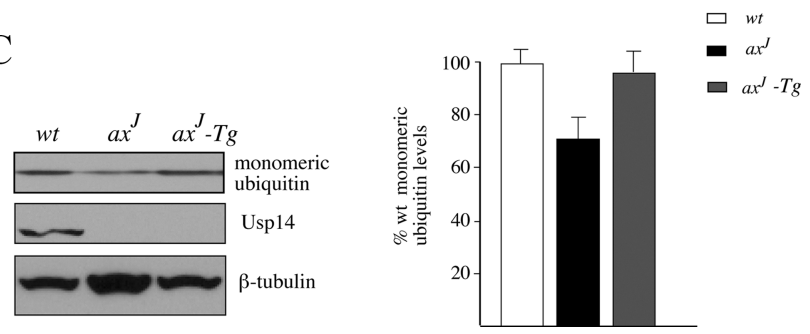

Figure 9. The Thy1-Usp14 transgene restores monomeric ubiquitin levels in the motor neuron circuit of $a x^{J}$ mice. $\boldsymbol{A}-\boldsymbol{C}$, Representative immunoblot of ubiquitin levels from spinal cords $(\boldsymbol{A})$, sciatic nerves $(\boldsymbol{B})$, and tibialis anterior muscles $(\boldsymbol{C})$ in wt, $a x^{\prime}$, and $a x^{\prime}-T g$ mice. Blots were also probed for Usp14 and neurofilament heavy chain (NF-H). $\beta$-Tubulin was used as a loading control. Graphs depict quantitation of monomeric ubiquitin levels. Error bars represent SE $(n=$ 3 mice per genotype).

steady-state levels of free and conjugated ubiquitin in synaptosomal fractions from wt and $a x^{J}$ mice. As previously reported (Anderson et al., 2005), there was a 30\% reduction in free ubiquitin without any change in the levels of conjugated ubiquitin in the total brain extracts from $a x^{J}$ mice compared with wt controls (Fig. 10). In contrast, analysis of synaptosomal fractions revealed a $40 \%$ reduction in conjugated ubiquitin and a $60 \%$ reduction in free ubiquitin in the $a x^{J}$ mice compared with wt controls (Fig. 10 ), indicating that there was a decreased stability of synaptic ubiquitin in the Usp14-deficient $a x^{J}$ mice.

\section{Discussion}

The work described in this study demonstrates that the neuromuscular defects present in the $a x^{J}$ mice are likely to be caused by developmental abnormalities in the motor neuron endplate. Although loss of Usp14 results in pathological changes in motor neurons and skeletal muscles, restoration of Usp14 exclusively in the nervous system of $a x^{J}$ mice was sufficient to correct all of the neuromuscular phenotypes observed in the $a x^{J}$ mice. This dysfunction of the motor neuron circuit appears to be responsible for the reduced muscle mass, rigidity, and tremor in the $a x^{J}$ mice. Although the $a x^{J}$ phenotypes are characteristic of a motor neuron disease, we did not observe any significant loss of motor neurons 

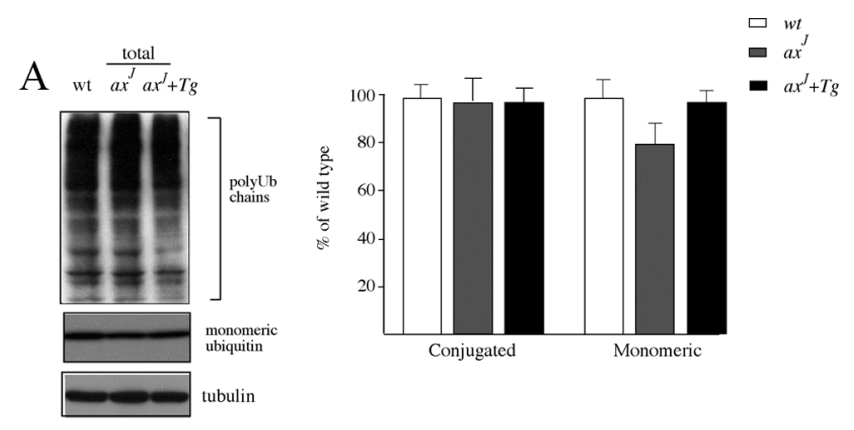

B
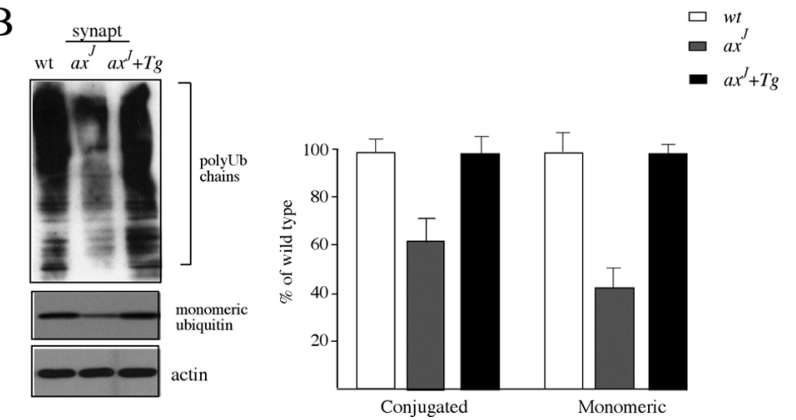

Figure 10. Synaptic loss of ubiquitin in $a x^{J}$ mice. $\boldsymbol{A}$, Representative immunoblot of total brain and synaptosomal (synapt) protein extracts from 4-week-old wt and $a x^{\prime}$ mice. Blots were probed for ubiquitin and either tubulin or actin as a loading control. $\boldsymbol{B}$, Graphs depict the quantitation of polyubiquitin chain levels and monomeric ubiquitin. Error bars represent SE ( $n=3$ mice per genotype). polyUb, Polyubiquitin.

or axon numbers in the $a x^{J}$ mice. Instead, we observed localized synaptic changes in the structure of the NMJ that included nerve terminal swellings and sproutings, nerve denervation, and neurofilament accumulation. These studies indicate that the $a x^{J}$ mice may serve as a new model to investigate the role of the UPS in diseases that affect motor neurons.

Our investigations of muscle AChR expression also indicated that there is defective nerve and muscle interaction in the $a x^{J}$ mice at 4 weeks of age. Previous studies have shown that muscle denervation results in increased expression of the $\alpha, \beta$, and $\delta \mathrm{AChR}$ subunits as well as the embryonic AChR $\gamma$ subunit (Merlie et al., 1984; Goldman et al., 1985; Shieh et al., 1987). During development, mRNA expression of the AChR $\gamma$ subunit is shut off and expression of the AChR $\varepsilon$ subunit mRNA is turned on (Hall and Sanes, 1993). Muscle denervation results in early increases in $\alpha \beta \gamma \delta$ expression, followed several days later by increased AChR $\varepsilon$ subunit expression (Goldman et al., 1985). In rats, the denervation of muscles has been shown to result in up to 50-100-fold increases in the expression of AChR subunit mRNAs (Merlie et al., 1984; Goldman et al., 1985). In comparison, the largest increase in AChR subunit mRNA expression in the $a x^{J}$ muscles at 4 weeks of age was a 30 -fold increase in the $\alpha$ subunit mRNA. However, the upregulation in AChR subunit expression in the $a x^{J}$ mice is consistent with a decrease in synaptic input to the muscle and possibly represents an attempt by the muscle to increase nerve-driven muscle activity.

Our studies suggest that the $a x^{J}$ neuromuscular disease is not caused by a loss of motor neurons in the ventral horn. Whereas no changes in total motor neuron number were seen in the $a x^{J}$ mice, we did observe fewer numbers of motor neurons of $>400$ $\mu \mathrm{m}^{2}$ in the $a x^{J}$ mice, which could result from either delayed maturation or increased motor neuron cell death. Since we were unable to detect any difference in activated caspase- 3 staining be- tween control and $a x^{J}$ mice, we favor the hypothesis of reduced neuronal development of the "large" motor neurons in the $a x^{J}$ mice.

The postnatal maturation of the NMJ involves the pruning of axons from muscles that are innervated by multiple motor neurons, the formation of a highly branched motor axon terminal, and the coordinated expansion of the nerve terminal and muscle fiber that leads to a three- to fourfold increase in the size of the NMJ (Sanes and Lichtman, 1999). In mice, these events occur during the first 2 weeks of postnatal development, allowing for the rapid growth and maturation of the muscle fibers. The process of motor endplate development is defective in the $a x^{J}$ mice, and large axon terminal swellings and sproutings are observed in several different muscle groups during the first 2 weeks of postnatal development. These axonal swellings and sproutings are enriched in phosphorylated neurofilaments and can be observed in the $a x^{J}$ mice as early as P7. However, it is unclear whether these nerve terminal sproutings represent an attempt at reinnervation of denervated muscles or whether the axon is attempting to make multiple contacts with the muscle to compensate for decreased NMJ activity. In $a x^{J}$ mice, the motor endplates located on the tibialis anterior muscles do not form the branched structure that is observed in wt mice by P14. By 3 weeks of age, the terminal swellings dramatically increase in size and disorganization of the AChR clusters can be seen in the $a x^{J}$ mice, suggesting that the terminal may be degenerating. These results support a model in which Usp14 plays an important role in the formation and function of mature NMJs.

The formation of swollen motor endplates is not uniform across all $a x^{J}$ muscle groups. In contrast to the tibialis anterior muscles, which demonstrate abnormal motor axon terminals at all of the NMJs, approximately half of the NMJ terminals on the diaphragms of the $a x^{J}$ mice appeared to be normal. Differential effects on NMJ pathology have also been reported in a mouse model of SMA, in which the diaphragm exhibited significantly less pathology than the intercostal muscles (Murray et al., 2008). Our previous studies using diaphragms from 4- to 6-week-old mice suggested that Usp14 is required for synaptic transmission at the NMJ (Wilson et al., 2002). We also demonstrated that a Thy1-Usp14 transgene could correct the locomotor defects and increase the lifespan of the $a x^{J}$ mice (Crimmins et al., 2006). Analysis of the expression patterns of the Thy1-Usp14 transgene demonstrated robust expression of Usp14 in the cortex and hippocampus and in the majority of the spinal cord motor neurons. The $a x^{J}-T g$ mice generated for this current study were phenotypically identical to wild-type mice with respect to muscle mass, strength, and viability (data not shown). Analysis of synaptic activity from the diaphragms of the $a x^{J}-T g$ mice described in this study demonstrated that restoration of Usp14 exclusively in the nervous system can correct all of the synaptic defects at the $a x^{J}$ NMJ back to near wild-type levels. These results indicate that, in addition to playing a role in NMJ development, Usp14 also functions to maintain synaptic activity at the NMJ.

Usp14 is a proteasome-associated deubiquitinating enzyme that has been shown to be important for maintaining ubiquitin levels in neurons (Borodovsky et al., 2001; Anderson et al., 2005; Crimmins et al., 2006). Through its association with the proteasome, Usp14 becomes catalytically active and deconjugates ubiquitin from substrates destined for proteasomal degradation $(\mathrm{Hu}$ et al., 2005; Crimmins et al., 2006). By facilitating ubiquitin recycling at the proteasome, Usp14 may act to stabilize ubiquitin pools at synaptic terminals. In support of this idea, loss of Usp14 appears to have the greatest effect on synaptic ubiquitin levels. Unlike total protein fractions, in which no changes in the levels of 
conjugated ubiquitin are seen between the $a x^{J}$ mice and controls, ubiquitin conjugation in synaptosomal fractions is reduced $40 \%$ in the $a x^{J}$ mice compared with controls. The decreased level of ubiquitin protein conjugates in the $a x^{J}$ synaptosomal fraction is consistent with impaired ubiquitin homeostasis at the synapse. Since ubiquitin has been shown to be transported down axons to replenish synaptic ubiquitin levels (Bizzi et al., 1991), the inability to recycle ubiquitin at the terminals of the motor neurons would have significant affects on the pool of ubiquitin required for targeting proteins for proteasomal degradation. It is also possible that the synaptosomal fraction may represent a more pure neuronal extract, and the differences observed in ubiquitin conjugates between the $a x^{J}$ mice and the controls may be detected only when the background levels of glial ubiquitinated protein conjugates are removed from the total brain extract.

Our studies have also demonstrated that muscle ubiquitin levels are responsive to the expression of Usp14 in the nervous system. Whereas it is possible that stabilization of ubiquitin pools in the muscle may require a specific level of neuronal activity, further studies will be required to determine the role of presynaptic Usp14 in regulating postsynaptic ubiquitin levels.

Although motor neuron disease is typically characterized by a loss of motor neurons, recent reports have demonstrated that the earliest structural defects in mouse models of SMA appear distally and involve the neuromuscular synapse (Kariya et al., 2008; Murray et al., 2008; Kong et al., 2009). Similar to what we observe in the $a x^{J}$ mice, the SMA phenotypes at the NMJ include poor arborization of axon terminals, presynaptic neurofilament accumulation, impaired maturation of AChR clustering into pretzel-like structures, and reduced muscle development. In addition, mis-sense mutations in the ubiquitin E1-activating enzyme have been linked to XL-SMA (Ramser et al., 2008), indicating that decreased protein ubiquitination may underlie the disease process in this form of infantile SMA. These findings suggest that a common biochemical pathway may be affected in both the SMA and $a x^{J}$ mice and that further studies on the $a x^{J}$ mice may provide key insights into the pathological mechanisms underlying SMA and other motor neuron disorders.

The data reported in this study show that Usp14 is essential for the postnatal maturation of the peripheral nervous system. It is tempting to speculate that the previously described postnatal defects in the CNS of the $a x^{J}$ mice (D'Amato and Hicks, 1965) are also caused by proteasomal dysfunction and subsequent ubiquitin loss. Since the nervous system undergoes extensive remodeling during postnatal development, maintenance of synaptic levels of ubiquitin is crucial for targeting proteins to the proteasome for degradation. Although the exact role Usp14 plays in NMJ development is not known, we hypothesize that the catalytic activity of Usp14 is critical for ubiquitin recycling at the proteasome. By regulating ubiquitin pools at the nerve terminal, Usp14 would therefore be able to modulate ubiquitin-dependent processes required during synaptic development.

\section{References}

Adams L, Carlson BM, Henderson L, Goldman D (1995) Adaptation of nicotinic acetylcholine receptor, myogenin, and MRF4 gene expression to long-term muscle denervation. J Cell Biol 131:1341-1349.

Alves-Rodrigues A, Gregori L, Figueiredo-Pereira ME (1998) Ubiquitin, cellular inclusions, and their role in neurodegeneration. Trends Neurosci 21:516-520.

Anderson C, Crimmins S, Wilson JA, Korbel GA, Ploegh HL, Wilson SM (2005) Loss of Usp14 results in reduced levels of ubiquitin in ataxia mice. J Neurochem 95:724-731.

Bizzi A, Schaetzle B, Patton A, Gambetti P, Autilio-Gambetti L (1991) Axonal transport of two major components of the ubiquitin system: free ubiquitin and ubiquitin carboxyl-terminal hydrolase PGP 9.5. Brain Res 548:292-299.

Blondet B, Carpentier G, Ait-Ikhlef A, Murawsky M, Rieger F (2002) Motoneuron morphological alterations before and after the onset of the disease in the wobbler mouse. Brain Res 930:53-57.

Borodovsky A, Kessler BM, Casagrande R, Overkleeft HS, Wilkinson KD, Ploegh HL (2001) A novel active site-directed probe specific for deubiquitylating enzymes reveals proteasome association of USP14. EMBO J 20:5187-5196.

Cifuentes-Diaz C, Nicole S, Velasco ME, Borra-Cebrian C, Panozzo C, Frugier T, Millet G, Roblot N, Joshi V, Melki J (2002) Neurofilament accumulation at the motor endplate and lack of axonal sprouting in a spinal muscular atrophy mouse model. Hum Mol Genet 11:1439-1447.

Collard JF, Côté F, Julien JP (1995) Defective axonal transport in a transgenic mouse model of amyotrophic lateral sclerosis. Nature 375:61-64.

Côté F, Collard JF, Julien JP (1993) Progressive neuronopathy in transgenic mice expressing the human neurofilament heavy gene: a mouse model of amyotrophic lateral sclerosis. Cell 73:35-46.

Crimmins S, Jin Y, Wheeler C, Huffman AK, Chapman C, Dobrunz LE, Levey A, Roth KA, Wilson JA, Wilson SM (2006) Transgenic rescue of ataxia mice with neuronal-specific expression of ubiquitin-specific protease 14 . J Neurosci 26:11423-11431.

Crimmins S, Sutovsky M, Chen PC, Huffman A, Wheeler C, Swing DA, Roth K, Wilson J, Sutovsky P, Wilson S (2009) Transgenic rescue of ataxia mice reveals a male-specific sterility defect. Dev Biol 325:33-42.

D'Amato CJ, Hicks SP (1965) Neuropathologic alterations in the ataxia (paralytic) mouse. Arch Pathol 80:604-612.

De Vos KJ, Grierson AJ, Ackerley S, Miller CC (2008) Role of axonal transport in neurodegenerative diseases. Annu Rev Neurosci 31:151-173.

Dodd PR, Hardy JA, Oakley AE, Edwardson JA, Perry EK, Delaunoy JP (1981) A rapid method for preparing synaptosomes: comparison with alternative procedures. Brain Res 226:107-118.

Dong XP, Li XM, Gao TM, Zhang EE, Feng GS, Xiong WC, Mei L (2006) Shp2 is dispensable in the formation and maintenance of the neuromuscular junction. Neurosignals 15:53-63.

Feng G, Mellor RH, Bernstein M, Keller-Peck C, Nguyen QT, Wallace M, Nerbonne JM, Lichtman JW, Sanes JR (2000) Imaging neuronal subsets in transgenic mice expressing multiple spectral variants of GFP. Neuron 28:41-51.

Gama Sosa MA, Friedrich VL Jr, DeGasperi R, Kelley K, Wen PH, Senturk E, Lazzarini RA, Elder GA (2003) Human midsized neurofilament subunit induces motor neuron disease in transgenic mice. Exp Neurol 184:408-419.

Glickman MH, Ciechanover A (2002) The ubiquitin-proteasome proteolytic pathway: destruction for the sake of construction. Physiol Rev 82:373-428.

Goldman D, Boulter J, Heinemann S, Patrick J (1985) Muscle denervation increases the levels of two mRNAs coding for the acetylcholine receptor alpha-subunit. J Neurosci 5:2553-2558.

Goldman D, Brenner HR, Heinemann S (1988) Acetylchomine receptor $\alpha$-, $\beta-, \gamma-$, and $\delta$-subunit mRNA levels are regulated by muscle activity. Neuron 1:329-333.

Hall ZW, Sanes JR (1993) Synaptic structure and development: the neuromuscular junction. Cell 10:99-120.

Hu M, Li P, Song L, Jeffrey PD, Chenova TA, Wilkinson KD, Cohen RE, Shi Y (2005) Structure and mechanisms of the proteasome-associated deubiquitinating enzyme USP14. EMBO J 24:3747-3756.

Kariya S, Park GH, Maeno-Hikichi Y, Leykekhman O, Lutz C, Arkovitz MS, Landmesser LT, Monani UR (2008) Reduced SMN protein impairs maturation of the neuromuscular junctions in mouse models of spinal muscular atrophy. Hum Mol Genet 15:2552-2569.

Kim JS, Kosek DJ, Petrella JK, Cross JM, Bamman MM (2005) Resting and load-induced levels of myogenic gene transcripts differ between older adults with demonstrable sarcopenia and young men and women. J Appl Physiol 99:2149-2158.

Kishino T, Lalande M, Wagstaff J (1997) UBE3A/E6-AP mutations cause Angelman syndrome. Nat Genet 15:70-73.

Kondo A, Iwaki T, Tateishi J, Kirimoto K, Morimoto T, Oomura I (1986) Accumulation of neurofilaments in a sporadic case of amyotrophic lateral sclerosis. J Psychiatry Neurol 40:677-684.

Kong L, Wang X, Choe DW, Polley M, Burnett BG, Bosch-Marcé M, Griffin JW, Rich MM, Sumner CJ (2009) Impaired synaptic vesicle release and 
immaturity of neuromuscular junctions in spinal muscular atrophy mice. J Neurosci 29:842-851.

Lee VM, Elder GA, Chen LC, Liang Z, Snyder SE, Friedrich VL Jr, Lazzarini RA (1992) Expression of human mid-sized neurofilament subunit in transgenic mice. Brain Res Mol Brain Res 15:76-84.

Lyon MF (1955) Ataxia, a new recessive mutant of the house mouse. J Hered 46:77-79.

Merlie JP, Isenberg KE, Russell SD, Sanes JR (1984) Denervation supersensitivity in skeletal muscle: analysis with a cloned cDNA probe. J Cell Biol 99:332-335.

Mishina M, Takai T, Imoto K, Noda M, Takahashi T, Numa S, Methfessel C, Sakmann B (1986) Molecular distinction between fetal and adult forms of muscle acetylcholine receptor. Nature 32:406-411.

Murray LM, Comley LH, Thomson D, Parkinson N, Talbot K, Gillingwater TH (2008) Selective vulnerability of motor neurons and dissociation of pre- and post-synaptic pathology at the neuromuscular junction in mouse models of spinal muscular atrophy. Hum Mol Genet 17:949-962.

Osaka H, Wang YL, Takada K, Takizawa S, Setsuie R, Li H, Sato Y, Nishikawa K, Sun YJ, Sakurai M, Harada T, Hara Y, Kimura I, Chiba S, Namikawa K, Kiyama H, Noda M, Aoki S, Wada K (2003) Ubiquitin carboxy-terminal hydrolase L1 binds to and stabilizes monoubiquitin in neuron. Hum Mol Genet 12:1945-1958.

Ramser J, Ahearn ME, Lenski C, Yariz KO, Hellebrand H, von Rhein M, Clark RD, Schmutzler RK, Lichtner P, Hoffman EP, Meindl A, BaumbachReardon L (2008) Rare missense and synonymous variants in UBE1 are associated with X-linked infantile spinal muscular atrophy. Am J Hum Genet 82:188-193.
Sanes JR, Lichtman JW (1999) Development of the vertebrate neuromuscular junction. Annu Rev Neurosci 22:389-442.

Sanes JR, Lichtman JW (2001) Induction, assembly, maturation and maintenance of a postsynaptic apparatus. Nat Rev Neurosci 2:791-805.

Shieh BH, Ballivet M, Schmidt J (1987) Quantitation of an alpha subunit splicing intermediate: evidence for transcriptional activation in the control of acetylcholine receptor expression in denervated chick skeletal muscle. J Cell Biol 104:1337-1341.

Thrower JS, Hoffman L, Rechsteiner M, Pickart CM (2000) Recognition of the polyubiquitin proteolytic signal. EMBO J 19:94-102.

Tu PH, Elder G, Lazzarini RA, Nelson D, Trojanowski JQ, Lee VM (1995) Overexpression of the human NFM subunit in transgenic mice modifies the level of endogenous NFL and the phosphorylation state of NFH subunits. J Cell Biol 129:1629-1640.

Walters BJ, Campbell SL, Chen PC, Taylor AP, Schroeder DG, Dobrunz LE, Artavanis-Tsakonas K, Ploegh HL, Wilson JA, Cox GA, Wilson SM (2008) Differential effects of Usp14 and Uch-L1 on the ubiquitin proteasome system and synaptic activity. Mol Cell Neurosci 39:539-548.

Wilson SM, Bhattacharyya B, Rachel RA, Coppola V, Tessarollo L, Householder DB, Fletcher CF, Miller RJ, Copeland NG, Jenkins NA (2002) Synaptic defects in ataxia mice result from a mutation in Usp14, encoding a ubiquitin-specific protease. Nat Genet 32:420-425.

Xu Z, Cork LC, Griffin JW, Cleveland DW (1993) Increased expression of neurofilament subunit NF-L produces morphological alterations that resemble the pathology of human motor neuron disease. Cell 73:23-33.

Yi JJ, Ehlers MD (2007) Emerging roles for ubiquitin and protein degradation in neuronal function. Pharmacol Rev 59:14-39. 